\title{
Documentation of the Clinical Blood Transfusion Practice at a Teaching and Referral Hospital in Western Kenya
}

\author{
Japheth Chebii Kipkulei ${ }^{1}$, Nathan Gyabi Buziba ${ }^{1}$, Simeon Kipkoech Mining ${ }^{2}$ \\ ${ }^{1}$ Department of Haematology and Blood Transfusion, School of Medicine, College of Health Sciences, Moi University, Eldoret, Kenya \\ ${ }^{2}$ Department of Immunology, School of Medicine, College of Health Sciences, Moi University, Eldoret, Kenya
}

Email address:

jkipkulei@gmail.com (J. C. Kipkulei)

\section{To cite this article:}

Japheth Chebii Kipkulei, Nathan Gyabi Buziba, Simeon Kipkoech Mining. Documentation of the Clinical Blood Transfusion Practice at a Teaching and Referral Hospital in Western Kenya. American Journal of Health Research. Vol. 7, No. 1, 2019, pp. 8-11.

doi: 10.11648/j.ajhr.20190701.12

Received: December 12, 2018; Accepted: January 22, 2019; Published: February 15, 2019

\begin{abstract}
Blood transfusion is an essential component of modern health care. It can restore normal life expectancy and improve quality of life when used safely. Blood is scarce, costly and its use could be associated. with complications. Good clinical practice, which includes proper documentation, ensures safe and effective transfusion practice. The objective of the study was to analyze the process of documenting the clinical blood transfusion practice at public teaching and referral hospital. A hospital based medical chart review of 384 patients who were transfused from June 2013 to November 2013 was carried out. Systematic random sampling method was used to sample the patient medical charts and a data was collected using a structured data collection. Data was analyzed using frequency tables and is presented in form of text, tables and charts. Approval was obtained from Institutional Research and Ethical Committee of Moi University and the patient's medical records were deidentified. The median age of the recipients was 31.5 years (IQR 13,45.8) and the range was 1 day to 89 years. Females comprised $55.2 \%$ of the recipients. The indication of the transfusion, pre-transfusion $\mathrm{Hb}$, consent, blood and blood product unit number, start times, duration of transfusion and observations of vital signs were documented in the charts of $91.1 \% .99 .0 \%$, $0.8 \%, 73.4 \%, 43 \%, 47.1 \%$ and $27.6 \%$ of all the recipients respectively. It was concluded that there were inadequacies in the documentation of the transfusion process. The strategies of clinical audit and continuing medical education of health workers ought to be applied in order to improve the documentation of the clinical practice of blood transfusion. In addition, studies to establish the reasons for inadequate documentation of the transfusion process should be carried out.
\end{abstract}

Keywords: Documentation, Blood Transfusion Practice, Transfusion Process

\section{Introduction}

Blood transfusion is an essential component of modern health care. It can restore normal life expectancy and improve quality of life when used safely. According to World Health Organization (WHO) [1] someone in the world needs blood every second. Although blood transfusion is lifesaving, its use is associated with both infectious and non-infectious complications. Blood is also a scarce and costly resource. In order to minimize the risks and the costs associated with blood use, safe and effective blood transfusion practice has to be ensured. The two main elements for safe and effective transfusion are sufficient supply of safe blood and good clinical practice. Good clinical practice contributes to safe and effective transfusion by ensuring that the right blood and blood product is given to the right patient at the right time, appropriate decision-making about the appropriate use of blood based on assessment of clinical findings and laboratory parameters, and the monitoring of patients for adverse effects of transfusion and their management if they occur and documentation of the process [2].

The clinical practice of blood transfusion is a complex multi-step process involving professionals of different background, including clinicians and nurses. The key steps include the decision to transfuse, obtaining an informed consent, taking and labeling of blood samples, collecting of blood from the laboratory, administration and monitoring of the recipients. The entire process of clinical blood transfusion practice has to be well documented. Good record keeping is an essential component in the provision of safe and effective health care [3]. In addition, proper documentation can also 
prevent future costs resulting from malpractice claim as cases of malpractice are frequently decided based on the documentation that occurred [4]. The aim of this study was to assess the adequacy of the documentation of the clinical blood transfusion process in a public Referral and Teaching Hospital, in order to provide information and guide initiatives for improving the quality of transfusion practices.

\section{Methodology}

This was a retrospective hospital-based chart review carried out at Moi Teaching and Referral Hospital which is a 900-bed capacity hospital located in Eldoret town, Kenya and it serves western Kenya, parts of Southern Uganda and South Sudan.

The study targeted patients who were admitted to the general wards of the hospital and were transfused whole blood or packed red cells between the months of June to November 2013. A sample of 384 patient charts were sampled using systematic random sampling method. Data was collected using a structured data collection form and information was extracted from the clinical notes, laboratory request forms, blood transfusion chart and the nursing notes. The information collected included data on age, gender, clinical department, blood and blood product transfused and documentation of the transfusion process (indication, pretransfusion $\mathrm{Hb}$, consent, time taken from ordering of blood to arrival in the ward, time taken from arrival of the unit to initiation, start times and observations of vital signs). The data was entered into SPSS software version 20 and it was summarized and analyzed using frequency tables.

An approval was obtained from Institutional Research and Ethical Committee (IREC) of Moi University and Moi Teaching and Referral Hospital. The patients' medical records were de-identified.

\section{Results}

\subsection{Demographic and Clinical Characteristics}

A total of 384 patient medical records were reviewed. The median age of the patients (IQR) was $31.5(13,45.8)$ and the range was 1 day to 89 years. Females comprised $172(44.8 \%)$ of the recipients. Of all the transfused patients, 59.9\% (230) were admitted to the medical and surgical wards, with the majority being transfused due to anaemia $(62.5 \%)$. Whole blood was transfused to $60.2 \%$ of the recipients. The demographic and clinical characteristics of the transfusion recipients is as shown in table 1 .

Table 1. The demographic and clinical characteristics of the recipients.

\begin{tabular}{lll}
\hline & Frequency & Percent (\%) \\
\hline Age groups (years) & & \\
$0-4$ & 54 & 14.0 \\
$5-14$ & 52 & 13.5 \\
$15-24$ & 31 & 8.0 \\
$25-34$ & 78 & 20.2 \\
$35-44$ & 71 & 18.4 \\
$45-54$ & 41 & 10.6 \\
\hline
\end{tabular}

\begin{tabular}{lll}
\hline & Frequency & Percent (\%) \\
\hline $55-64$ & 23 & 6.0 \\
$65+$ & 34 & 8.8 \\
Sex & & \\
Male & 172 & 44.8 \\
Female & 212 & 55.2 \\
Clinical department & & \\
Medical & 112 & 29.2 \\
Surgical & 117 & 30.5 \\
Reproductive health & 75 & 19.5 \\
Child health & 80 & 20.8 \\
Indication for transfusion & & \\
Anaemia & 240 & 62.5 \\
Elective surgery & 55 & 13.3 \\
Haemorrhage & 55 & 13.3 \\
Not documented & 34 & 8.9 \\
Blood transfused & & \\
Whole blood & 231 & 60.2 \\
Packed red & 153 & 39.8 \\
\hline
\end{tabular}

\subsection{Documentation of the Clinical Blood Transfusion}

The duration form ordering of blood to arrival in the ward was documented for all the recipients and it within 24 hours for most of the patients $344(89.6 \%)$. The reasons for the delay for those whose blood took more than 24 hours to arrive in the ward were documented for only $40 \%(n=16 / 40)$ of the patients. The reason given for the delay in all the documented cases was lack of blood in the blood bank.

The indication of the transfusion was documented in $8.9 \%$ $(34 / 384)$ while the pre-transfusion $\mathrm{Hb}$ was documented in $99.0 \%(380 / 384)$ of the recipients. Only $0.8 \%(3 / 384)$ of patients had documented evidence of informed consent in their medical records. The duration of completion of the transfusion was documented in $47.1 \%(181 / 384)$ and it was within $4 \mathrm{hrs}$ for $33.9 \% \quad(130 / 384)$ of the patients. Documentation of transfusion start times was carried out in $57.0 \%(219 / 384)$ of the transfusion recipients and the number of recipients who had blood product unit number and vital signs recorded were $73.4 \%(282 / 384)$ and $27.9 \%(107 / 384)$ respectively. The documentation of the various clinical transfusion processes is shown in table 2 and the recording of vital signs before, during and after transfusion is as shown in figure 1 .

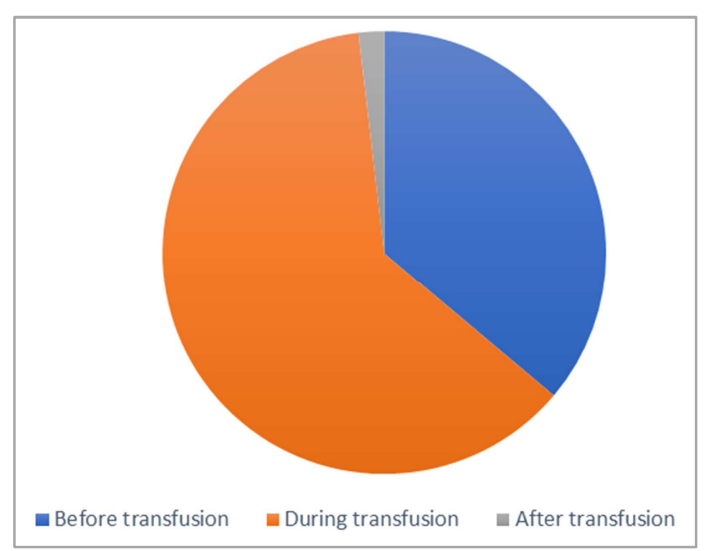

Figure 1. Observations of the vital signs before, during and after transfusion. 
Table 2. The frequency and percentages of the documentation of the clinical transfusion processes.

\begin{tabular}{lll}
\hline Transfusion processes & $\begin{array}{l}\text { Documented } \\
\text { n (\%) }\end{array}$ & $\begin{array}{l}\text { Undocumented } \\
\text { n (\%) }\end{array}$ \\
\hline Indication & $350(91.1)$ & $34(8.9)$ \\
Pre-transfusion $\mathrm{Hb}$ & $380(99.0)$ & $4(1.0)$ \\
Consent & $3(0.8)$ & $381(99.2)$ \\
Blood unit number & $282(73.4)$ & $102(26.6)$ \\
Start times & $219(57.0)$ & $165(53.0)$ \\
Duration of transfusion & $181(47.1)$ & $203(52.9)$ \\
Observation of Vital signs & $277(72.1)$ & $107(27.9)$ \\
\hline
\end{tabular}

\section{Discussion}

There were inadequacies regarding documentation of the transfusion process. There were no records for indication, pre-transfusion $\mathrm{Hb}$, informed consent, transfusion start times, duration of completion of the transfusion, blood and blood product unit number in and vital signs in $8.9 \%, 1.0 \%, 99.2 \%$, $57 \%, \quad 52.9 \% \%, \quad 26.6 \%$ and $27.9 \%$ of all recipients, respectively. There were also no records for vital signs before, during and after transfusion in $69.9 \% \%, 48.2 \%$ and $98.4 \%$ of patients respectively. Our findings compare with those of other studies [5- 9]. The study by Audet [5] showed that patient consent was documented in only $1 \%(2 / 155)$ of transfusion events. As our study was a retrospective medical chart review, it cannot be ascertained whether the consent was not documented or it was not obtained at all from the patients in the first place. It is also of importance to note that there was no specific consent form for blood transfusion in our hospital.

In a study by de Graaf [6]. the documentation of the transfusion process was carried in around $50 \%$ of the patients but this was done only briefly and inaccurately. In the same study, blood product number, the starting times and duration of the procedure were documented occasionally, but not consistently while the pre and post transfusion vital signs were not recorded at all. A similar study by Natukunda [7]. found that there were no records for pre-transfusion hemoglobin, transfusion start-times and vital signs in $30.2 \%$, $21.5 \%$ and $97.6 \%$ of all recipients respectively. Proper and diligent monitoring of the patients receiving a blood transfusion for adverse signs or symptoms, can help prevent or manage a potentially fatal reaction such as haemolytic reaction caused by an earlier process error or an unavoidable physiologic condition [10].

From our findings, it appeared that forty patients (10.4\%) had to wait for blood for more than 24 hours after being ordered before getting the transfusion. The main reason for the delay was lack of blood in the blood bank. In their study, Mosha [11]. found that $8 \%$ of patients had to wait for more than 6 hours from the doctor's decision for a blood transfusion to the actual initiation of it due to lack of blood. The limited availability of blood has been reported by the World Health Organization [12]. and the Kenya National Blood transfusion Service [(13). The delay in initiating blood transfusion might increase mortality due severe anaemia [1416]. In a model adjusting for such features of severe illness,
Thomas [14]. showed that children who had a transfusion ordered and given on the same day compared with those with a delay in receiving blood ( 1 day after prescription) had lower mortality $(\mathrm{OR}=0.58,95 \% \mathrm{CI}=0.38-0.87)$, whereas those not transfused had higher mortality $(\mathrm{OR}=1.8,95 \% \mathrm{CI}$ $=1.3-2.49$ ).

In regards to the documentation of the duration of the blood transfusion, completion of the transfusion was more than the recommended time of 4 hours in $13.0 \%$ of the patients. This finding differs from that of studies by Reis (3) and Mosha [11]., where the duration of the transfusion was more than the recommended time in $8 \%$ and $40 \%$ of the recipients respectively. However, in our study, $57 \%$ of the recipients did not have any documentation of the start times of the transfusion. Long transfusion time increases risk of bacterial growth of the blood [17-18]. It may also delay the time before a viable $\mathrm{Hb}$ level is restored.

One of the major limitations of our study is that it is a retrospective study carried out in a single centre. However, our study findings provided insights into the current practice of documentation of blood transfusion process at a regional hospital and came up with recommendations aimed at ensuring the quality and safety of blood transfusion throughout the process

\section{Conclusion and Recommendation}

The documentation of the blood transfusion process was inadequate which could lead to unsafe administration of blood and blood components. The clinical transfusion processes with the most documentation inadequacies were the informed consent, start times and duration of the transfusion. The clinicians and nursing staff involved in blood transfusion ought to be trained on the importance of proper documentation of the transfusion process. Furthermore, the hospital needs to adopt the strategies of clinical audit to monitor the documentation of clinical blood transfusion process. A consent form dedicated solely for the blood transfusion service should be designed and utilized and lastly the reasons for the poor documentation of the transfusion process and non-adherence to the national guidelines, hence unsatisfactory level of appropriate blood use needs to be established.

\section{References}

[1] World Health Organization. Universal Access to Blood Transfusion [Internet]. Geneva. WHO; [cited 2013 May 4]. Available from: http://www.who.int/bloodsafety/publications/Universal Accessto Safe BT. Pdf.

[2] Murphy MF, Stanworth SJ, Yazer M. Transfusion practice and safety: current status and possibilities for improvement. Vox Sang. 2011 Jan; 100 (1): 46-59.

[3] Nursing and Midwifery Council. Record Keeping: Guidance for Nurses and Midwives [Internet]. NMC; [cited $2017 \mathrm{Jul}$ 25]. Available from: www.nipec.n-i.nhs.uk//nmcGuidance Record Keeping Guidancefor Nursesand Midwive. 
[4] Frank-Stromborg M, Christensen A, Elmhurst D. Nurse documentation: not done or worse, done the wrong way--Part I. Oncol Nurs Forum. 2001 May; 28 (4): 697-702.

[5] Audet AM, Goodnough LT, Parvin CA. Evaluating the appropriateness of red blood cell transfusions: the limitations of retrospective medical record reviews. Int $\mathrm{J}$ Qual Health Care. 1996 Feb; 8 (1): 41-9.

[6] De Graaf JD, Kajja I, Bimenya GS, Postma MJ, Sibinga CT Bedside practice of blood transfusion in a large teaching hospital in Uganda: An observational study. Asian J Transfus Sci. 2009 Jul; 3 (2): 60-5.

[7] Natukunda B, Schonewille H, Smit Sibinga CT. Assessment of the clinical transfusion practice at a regional referral hospital in Uganda. Transfus Med. 2010 Jun; 20 (3): 134-9.

[8] Grewal P, Neffendorf J, Williams B. The quality of blood transfusion documentation and consent in surgical patients at a central London teaching hospital. What should we be teaching to maintain good transfusion practice? International Journal of Surgery. 2012 Jan 1; 10 (8): S78.

[9] Dos Reis VN, Paixão IB, Perrone ACA de SJ, Monteiro MI, dos Santos KB. Transfusion monitoring: care practice analysis in a public teaching hospital. Einstein (Sao Paulo). 2016; 14 (1): 41-6.

[10] Fastman BR, Kaplan HS. Errors in transfusion medicine: have we learned our lesson? Mt Sinai J Med. 2011 Dec; 78 (6): 854-64.

[11] Mosha D, Poulsen A, Reyburn H, Kituma E, Mtei F, Bygbjerg IC. Quality of paediatric blood transfusions in two district hospitals in Tanzania: a cross-sectional hospital based study. BMC Pediatr. 2009 Aug 14; 9: 51.
[12] World Health Organization. Global Status Report on Blood Safety and Availability [Internet]. Geneva. WHO; [cited 2017 Jun 10]. Available from: apps.who.int/iris/bitstream/10665/254987/1/9789241565431eng. pdf.

[13] Merab E, Osota M. State of Kenya's Blood Banks. Daily Nation. 2015 Jun 17;35-6.

[14] Thomas J, Ayieko P, Ogero M, Gachau S, Makone B, Nyachiro W, et al. Blood Transfusion Delay and Outcome in County Hospitals in Kenya. Am J Trop Med Hyg. 2017 08; 96 (2): 511-7.

[15] Lackritz EM, Campbell CC, Ruebush TK, Hightower AW, Wakube W, Steketee RW, et al. Effect of blood transfusion on survival among children in a Kenyan hospital. Lancet. 1992 Aug 29; 340 (8818): 524-8.

[16] Lackritz EM, Ruebush TK, Zucker JR, Adungosi JE, Were JB, Campbell CC. Blood transfusion practices and blood-banking services in a Kenyan hospital. AIDS. 1993 Jul; 7 (7): 995-9.

[17] Norfok D. Handbook of Transfusion Medicine [Internet]. 5th ed. London: TSO: United Kingdom Book Services; [cited 2018 Nov 27]. Available from: https://www.transfusionguidelines.org//transfusionhandbook $/ 5$ th $\% 20$ Handbook $\% 20$.

[18] Johnson V, Langeberg A, Taye-Makuria A, Sandler SG. Temperature-sensitive labels for containers of RBCs. Am J Clin Pathol. 2006 Sep; 126 (3): 406-10. 